\title{
CiUdadanía liberal, proyecto DE VIDA Y AUTODETERMINACIÓN: LOS DERECHOS INDIVIDUALES COMO CAMINO O COMO LÍMITE DE LA CONSTRUCCIÓN DE LA IDENTIDAD*
}

\section{LIBERAL CITIZENSHIP, PROJECT OF LIFE AND SELF-DETERMINATION: INDIVIDUAL RIGHTS AS A PATH OR LIMIT TOWARDS THE CONSTRUCTION OF IDENTITY}

\author{
Julián Daniel González-Escallón**
}

Fecha de recepción: 8 de marzo de 2017

Fecha de aceptación: 29 de marzo de 2017

Disponible en linea: 30 de noviembre de 2017

\section{Para citar este artículo/To cite this article}

\begin{abstract}
González-Escallón, Julián Daniel, Ciudadanía liberal, proyecto de vida y autodeterminación: los derechos individuales como camino o como límite de la construcción de la identidad, 135 Vniversitas, 165-192 (2017). http:// dx.doi.org/10.11144/Javeriana.vj135.clpv

doi:10.11144/Javeriana.vj135.clpv
\end{abstract}

Este es un artículo de revisión bibliográfica inscrito en mi investigación en el doctorado en derecho de la Facultad de Jurisprudencia, Universidad del Rosario.

** Abogado en litigio de restitución de tierras de la Comisión Colombiana de Juristas, CCJ. ORCID: 0000-0002-0775-2956. Abogado, Pontificia Universidad Javeriana. Estudiante del doctorado en derecho, Universidad del Rosario. Contacto: jdgonzalezescallon@gmail.com

El autor agradece al profesor Wilson Herrera de la Escuela de Ciencias Humanas, de la Universidad del Rosario, por su incalculable ayuda en la construcción de este texto. Así mismo, al profesor Marco Velásquez, del Instituto Pensar, de la Pontificia Universidad Javeriana, por sus oportunas notas y apreciaciones. 


\section{RESUMEN}

Este artículo forma parte de una investigación doctoral, en la que pretendo localizar la discusión sobre la construcción individual de identidad en las sociedades liberales, desde la perspectiva de la filosofía jurídica y moral. El documento ubica dentro del debate sobre la autodeterminación y la formulación de un proyecto de vida, la clave para la efectividad o no de los derechos liberales para proteger estas libertades y hacerlas ejecutables. En este sentido, se explora el enfoque liberal clásico, en el cual el acceso a las garantías elementales de autodeterminación mantiene un parámetro de neutralidad, en la medida en que el Estado garantiza que no impone de su parte una idea de buena vida que obligue a los ciudadanos a aceptar una cierta postura moral de lo que significa buenos principios y buenas costumbres, pero protegiendo la creación de desarrollos colectivos o individuales de diversos objetivos de vida. Se concluye que si bien hay una tradición liberal que desea hacer cumplir las garantías de autodeterminación y formulación del plan de vida, estas instituciones jurídicas pueden no ser suficientes para asegurar que las identidades minoritarias alcancen el pleno alcance del derecho de autodeterminación.

Palabras clave: Autodeterminación; plan de vida; liberalismo; identidad; comunitarismo; pluralismo moral 


\section{ABSTRACT}

This article is part of a doctoral research, in which I seek to locate the discussion on individual construction of identity in liberal societies, from the perspective of legal and moral philosophy. The document seeks to find within the debate on self-determination and the formulation of a life project, the key to the effectiveness or not of the liberal rights to protect these freedoms and make them enforceable. In this sense, the classical liberal approach is explored, in which access to elementary guarantees of self-determination maintain a neutrality parameter, insofar as the State guarantees that it does not impose on its part an idea of good life that obliges citizens to accepting a certain moral posture of what means good principles and good morals, but protecting the creation of collective or individual developments of various life goals. It is concluded that although there is a liberal tradition that seeks to enforce the guarantees of self-determination and formulation of life plan, this legal institution may not be sufficient to ensure that minority identities reach the full scope of the self-determination right.

Keywords: Self-determination; life plan; liberalism; identity; communitarianism; moral pluralism

\section{SUMARIO}

INTRODUCCIÓN.- I. NEUTRALIDAD NORMATIVA Y LA PARADOJA DE LA LIBERTAD Individual y COMUnitaria.- $A$. ¿Cómo se construye el buen vivir?- $B$. Comunidad, Individuo y proyecto de vida.- Conclusiones.- Bibliografía. 
Hay un límite en la intervención legítima de la opinión colectiva en la independencia individual: encontrarlo y defenderlo contra toda invasión es tan indispensable a una buena condición de los asuntos humanos como la protección contra el despotismo político. John Stuart Mill, Sobre la libertad

Political freedom is freedom from coercion, nothing less nor more. Joseph Raz, The Morality of Freedom

\section{INTRODUCCIÓN}

La discusión que quiero plantear en la disertación doctoral se sitúa dentro del debate sobre la autonomía individual y la construcción de la identidad ${ }^{1}$ en las sociedades liberales. La premisa esencial de la discusión es la neutralidad moral de los ordenamientos políticos y legales que han integrado lo que es posible denominar instituciones políticas y filosóficas liberales ${ }^{2}$. En la postura clásica liberal, cada individuo puede decidir formar una vida y comportamiento, de acuerdo a sus valores, creencias y posturas. Esto, a su vez, es posible dentro del entendido de que el Estado y las instituciones jurídicas son "neutrales", lo que significa que las estructuras de derechos individuales y otras formas de control sobre los individuos,

1 Entenderé identidad en este contexto como lo describe Marina A. L. Oshana en el texto Autonomy and Self-Identity. La autora expone su idea alrededor de un caso imaginario, en el cual la madre de esta profesora vive en la indigencia y requiere su apoyo financiero. Sobre este caso base se dan variaciones. Por ejemplo, el caso de acuerdo al cual la ayuda financiera que la hija da a la madre indigente es utilizada por esta última para comprar drogas, o conducir otras actividades ilegales. El punto que este experimento mental quiere ilustrar, es hasta dónde puede la hija transigir en su ponderación en valores para seguir entregando recursos a su madre delincuente. La autora propone todo este ejercicio para ilustrar la identidad como una forma de contingencia moral, en la cual el individuo pondera valores en su interior sin los cuales no se reconocería a sí mismo: "no sería yo si...". Marina A. L. Oshana, Autonomy and Self-Identity, en Autonomy and the Challenges of Liberalism, 77-97, 81, 82 (John Christman \& Joel Anderson, eds., Cambridge University Press, Cambridge, 2005).

2 La neutralidad como valor en el liberalismo tiene un importante desarrollo teórico. Por ejemplo, John Rawls, Liberalismo politico, 35 (Fondo de Cultura Económica, FCE, México, 2015). También este mismo punto se señala en: JosePh RAZ, The Morality of Freedom, 110 (Oxford University Press, Oxford, 1986). Andrew D. Mason inicia su escrito con: "La idea según la cual el respeto a las personas requiere un estado neutral (en algún sentido) entre diferentes concepciones sobre la buena vida es un componente importante de la teoría liberal contemporánea. Es atractivo al menos en parte porque resuena con el pensamiento de acuerdo al cual el Estado debe ser imparcial en relación con sus ciudadanos. Los teóricos liberales tienen variadas concepciones sobre qué significa para un Estado ser neutral entre concepciones de cómo vivir, pero coinciden en que la neutralidad tiene consecuencias políticas sustantivas que exceden lo que, por ejemplo, los conservadores y los radicales entienden es demandado por la imparcialidad" (traducción propia). ANDREW D. MASON, Autonomy, Liberalism and State Neutrality, 40 The Philosophical Quarterly, 161, 433-452 (1990). Otro texto sobre la neutralidad como valor de las organizaciones liberales que vale la pena revisar es: Ronald Dworkin, Una cuestión de principios (Siglo XXI Editores, Madrid, Buenos Aires, 2012). 
protegen el derecho de cada ser humano a la autodeterminación ${ }^{3}$ sin establecer un modelo por medio de las leyes o de la política, que pretenda ser hegemónico y único, o que se señale como "la buena/única forma de vivir"4. En ese sentido, la llamada neutralidad es entonces el proyecto de no incluir absolutos morales como contenido doctrinario en el ordenamiento jurídico o como punto de partida político. Dicho de otro modo, el principio liberal de neutralidad implica que la concepción moral individual puede no estar determinada necesariamente por la verdad moral colectiva. Este principio de indeterminación moral es la regla elemental que guía el entendimiento político y legal: se trata del rechazo de plano del paternalismo y perfeccionismo moral. En este entendido, la autodeterminación es la disposición de ejercer la capacidad de elección entre las alternativas y así, con un norte moral construido o elegido individualmente, cada persona puede tomar la determinación moral que desee, escogiendo sus valores y prácticas de forma individual. Esta específica libertad de elección de modo de vida es lo que llamaré autodeterminación. Puesto de la manera más sencilla: la autonomía no es otra cosa que poder decidir por uno mismo la idea sobre lo bueno y lo malo y actuar en consecuencia.

De acuerdo a lo anterior, desde una perspectiva liberal, la autodeterminación juega un rol fundamental, influye en la forma en que se construyen sociedades multiculturales abiertas que, por consecuencia, se concreta en el pluralismo moral ${ }^{5}$. Por supuesto,

3 La autodeterminación es parte esencial dentro de la idea liberal de autonomía individual. Sobre el ejercicio racional de un proyecto de vida: John Rawls, Teoría de la justicia, 370-377 (Fondo de Cultura Económica, FCE, México, 2012). En este mismo sentido, la idea del reconocimiento de Axel Honneth también hace referencia a la forma en la cual se estructuran los proyectos de vida, y cómo la autodeterminación es la herramienta mediante la cual se construyen estos proyectos. Axel Honneth, Struggle for Recognition. The Moral Grammar of Social Conflicts, 174 (The MIT Press, Cambridge, Massachusetts, 1995). Por otro lado, un debate muy interesante sobre la autodeterminación y cómo se forma la agencia se encuentra en: SARAH Buss, Autonomous Action: SelfDetermination in the Passive Mode, 122 Ethics, 4, 647-691 (2012). Disponible en: http://www.jstor. org/stable/pdf/10.1086/666328.pdf?refreqid=excelsior\%3Aba601e4d03a3b33973f683c8c2503585

4 Sobre la relación entre la construcción de un proyecto de vida y la figuración individual de lo que encuentra moralmente positivo o negativo, Alan Gewirth señala: "La idea de control es central a la libertad; es lo que da a la libertad su valor como una característica genérica de acción. Involucra ser dueño de sí mismo, incluyendo no solo los propios comportamientos externos sino la experiencia interna individual; $\mathrm{y}$ se extiende a aspectos relevantes del entorno individual pues permean al sujeto. Tener un sentido justificado de ese tipo de control contribuye de forma importante a la construcción de un mejor yo" (traducción propia). Alan GewirTh, Self Fulfillment, 113 (Princeton University Press, Princeton, New Jersey, 1998)

5 Una forma de abordar el pluralismo moral es el reconocimiento de distintos órdenes jurídicos que responden a distintas formas de entender los valores básicos de la sociedad. Al respecto, puede verse 
para poder ejercer efectivamente la autodeterminación, es necesario el pluralismo moral como punto de partida, si se tiene en cuenta que la autodeterminación necesariamente implica escoger entre una variedad de opciones posibles. Sin las opciones, no hay ninguna capacidad de elección. El pluralismo moral requiere que la sociedad se comprometa a sostener el pacto político de permitir las libertades de sus miembros y darle cabida a la expresión de su individualidad. Así, las sociedades que establecen normativamente su contenido moral y lo que comunitariamente se define como la buena forma de vida, cierran posibilidades a sus miembros, al darles opciones en todo caso, pero reducidas. A forma de ejemplo, tomemos un Estado que propone la forma de vida cristiana como la forma de vida buena, pero no obliga a sus miembros a seguir el dogma ni a abrazar las costumbres cristianas, respetando en todo los derechos de los individuos no creyentes en el cristianismo. En principio, si este Estado no interviene en la forma de vida particular de cada individuo, y no incentiva en la práctica un estilo de vida mejor que el otro (por ejemplo, facilidades a los cristianos en subsidios, impuestos, etc., que no se extienden a los no cristianos) se preservaría el principio de neutralidad. Sin embargo, sin incentivos ni formulaciones legales y políticas, ¿cómo puede en la práctica un Estado promover un estilo de vida o un concepto de vida buena únicamente al formularlo? O puesto de otro modo: ¿puede un Estado promover valores no neutrales sin políticas de promoción directa de esos valores?

En principio, la estructura estatal y jurídica liberal resulta la más respetuosa de las creencias individuales, al replegar al Estado y permitir la construcción individual de la identidad, la elección y, en suma, la autodeterminación. A este respecto, los críticos del liberalismo señalan que la promesa de una neutralidad valorativa del Estado y de la sociedad no solo es inalcanzable, sino que además invisibiliza muchos tipos de violencia que anteceden a las sociedades liberales, y que ante la apuesta neutra de los mismos, no han podido ser señalados de manera clara y mucho menos combatidos ${ }^{6}$. Una

la discusión en: Sally Engle Merry, John Griffiths \& Brian Z. Tamanaha, Pluralismo jurídico (Siglo del Hombre Editores, Bogotá, 2007).

6 Ver una de las más fervorosas críticas a la estructura liberal y su pretendida neutralidad, en CATHARINE A. MacKinnon \& Richard Posner, Derecho y pornografía (Siglo del Hombre Editores, Bogotá, 1997). En este texto se pone de presente cómo ciertas formas de machismo se reproducen por medio 
crítica particularmente aguda viene de Joseph Raz, quien señala que cierto tipo de paternalismo moral es necesario dentro del liberalismo, dado que parte fundamental del liberalismo es crear un entorno dentro del cual sus ciudadanos puedan ejercer la autonomía de su voluntad. Para crear este tipo de sociedades, es necesario que valores como la libertad, la igualdad y cierto parámetro de justicia (vistos desde el discurso liberal) sean defendidos por encima de otros, lo que implica que la neutralidad no es absoluta y que sí hay apuestas claras por ciertas formas de entender la vida en sociedad. Uno de los ejemplos más claros: cuánta libertad individual es posible lograr sin la intervención del Estado en los asuntos personales? En este sentido, el enfoque diferencial se ha impuesto en muchas formas y distintas ocasiones, y es cada vez más popular.

Si bien en Colombia hay un número nutrido de iniciativas legislativas, judiciales y sociales sobre la inclusión de comunidades tradicionalmente excluidas de la discusión pública ${ }^{8} \mathrm{y}$, en consecuencia, de la aplicación plena de sus derechos, vale la pena preguntarse por el fundamento o la razón por la cual la autodeterminación de ciertos individuos parece no surtir los efectos inmediatos que en otros grupos se da por descontado. Un ejemplo de lo anterior, es cómo en los casos de personas homosexuales el ejercicio de su plan de vida implica no gozar de los mismos derechos que las personas heterosexuales ${ }^{9}$. En el fondo, lo anterior implica que su derecho a la autodeterminación no está garantizado, dado que deben cambiar

de la pornografía, y cómo el discurso liberal no toma posición frente a lo dañina que esta forma de prejuicio puede ser, precisamente por su principio de neutralidad.

7 Joseph Raz, The Morality of Freedom, 424-429 (Oxford University Press, Oxford, 1986).

8 Ley de cuotas (Ley 581 de 2000), interrupción voluntaria del embarazo (que inició por medio de la sentencia C-355-06), reconocimiento de derechos para parejas homosexuales (sentencia C-075-07), entre otros. Colombia, Ley 581 de 2000, por la cual se reglamenta la adecuada y efectiva participación de la mujer en los niveles decisorios de las diferentes ramas y órganos del poder público, de conformidad con los artículos 13, 40 y 43 de la Constitución Nacional y se dictan otras disposiciones, 44.026 Diario Oficial, 31 de mayo 2000. Disponible en: http://www.secretariasenado.gov.co/senado/ basedoc/ley_0581_2000.html.Colombia, Corte Constitucional, Sentencia C-355-06, 10 de mayo de 2006, magistrados ponentes Jaime Araújo-Rentería, Clara Inés Vargas-Hernández. Disponible en: http://www.corteconstitucional.gov.co/relatoria/2006/C-355-06.htm. Colombia, Corte Constitucional, Sentencia C-075-07, 7 de febrero de 2007, magistrado ponente Rodrigo Escobar-Gil. Disponible en: http://www.corteconstitucional.gov.co/relatoria/2007/c-075-07.htm

9 Si bien la brecha ha ido cerrándose y los avances en materia de derechos de la comunidad LGTBI han sido constantemente ensanchados por la Corte Constitucional, el debate al respecto de hasta dónde llega la igualación en derechos sigue siendo pieza importante de la discusión pública. Al respecto, Revista Semana, El poder gay en Colombia (25 de junio de 2016). Disponible en: http:// www.semana.com/nacion/articulo/lgbt-como-progresismo-e-igualdad-de-derechos/479178 
su plan de vida, si quieren acceder a otros derechos. En ese sentido, al menos, hay una ruptura del principio de neutralidad del Estado liberal. La aplicación y respuesta dispar de los ordenamientos jurídicos y de las comunidades políticas muestran una inconsistencia que vale la pena explorar. Hay que preguntarse entonces si la autodeterminación crece de manera silvestre, o quiénes de entre los seres humanos pueden aspirar a la autonomía. En ese sentido, la pregunta pasa de alguna forma por el aspecto legal y en esta intersección es donde se traslapan la filosofía política y la jurídica: ¿pueden los derechos fundamentales ser la herramienta suficiente para otorgar la emancipación y la autonomía individual que el discurso liberal promulga? ${ }^{10}$. Para exponer los elementos teóricos que esta pregunta reviste, es importante abordar el espectro amplio donde está situada, que encuentro en la discusión entre valores comunitarios e individuales. En ese sentido, pasaré a explorar la tensión entre comunitarismo e individualismo desde tres frentes: el debate sobre la autodeterminación individual y sus límites dentro de una comunidad, la construcción del plan vida y la construcción de la identidad.

\section{NEUTRALIDAD NORMATIVA Y LA PARADOJA DE LA LIBERTAD INDIVIDUAL Y COMUNITARIA}

De lo anteriormente mencionado, emergen algunos aspectos nodales de la discusión: el liberalismo político se pretende enmarcar en una propuesta moralmente neutral. Esta neutralidad consiste en no tomar parte activa en la determinación de qué es "vida bue$n a$ " o de cómo los individuos deben formar su existencia. En este entendido, la autonomía individual toma un papel cardinal en la discusión, dado que, mediante el repliegue del Estado como agente formador de la estructura moral de los individuos, los mismos deben tomar elecciones sobre qué consideran adecuado o no para

10 De cierta forma podría decirse que la pregunta pretende hacer crítica al liberalismo, esta crítica a los derechos no es de cualquier forma, una teoría novedosa. Al respecto, MARK Tushnet, An Essay on Rights, 62 Texas Law Review, 8, 1363-1402 (1984). Disponible en: http://www.dariaroithmayr. com/pdfs/assignments/Tushnet,\%20Essay\%20on\%20Rights.pdf. Del mismo modo, una forma estructurada del debate puede consultarse en DunCan Kennedy, A Critique of Adjudication (fin de siècle), capítulos 13 y 14 (Harvard University Press, Cambridge, Massachusetts, 1997). 
su vida y asumir la consecuencia de esas elecciones. El presupuesto de estas elecciones es entonces que todos quienes hacen parte de la comunidad están - en principio - capacitados para llevar a cabo los razonamientos y los procesos de toma de decisión suficientes para formular su plan de vida. A esta capacidad de toma de decisiones puede llamársele libertad interior o libertad positiva, si se tiene en cuenta que se trata de tener aptitudes cognitivas, racionales y aspiracionales suficientes para establecer un criterio sobre lo que considera moralmente correcto e incorrecto. Este tipo de libertad es necesario para formular el plan de vida. El otro tipo de libertad que se requiere es aquella que ofrece el liberalismo y que proviene del pacto civil: la libertad civil. Este tipo de libertad es la que concede la comunidad política para poder establecer fácticamente lo que cada ser humano desea hacer con su existencia. Los ejemplos abundan: cambios en la apariencia, opciones de identidad de género, hábitos de consumo, discurso y conducta, etc. De acuerdo al discurso liberal, el Estado procura las libertades, pero no las influye con un plan de vida determinado ${ }^{11}$.

Ahora bien, la no imposición de un plan de vida y la opción material de llevarlo a cabo se garantizan por medio de normas jurídicas que refuerzan la libertad individual, y proscriben el acoso o el señalamiento de otros miembros de la comunidad por las opciones escogidas $^{12}$. Por lo anterior, la idea del derecho liberal es proteger idénticamente a todos los miembros de la sociedad, al ofrecerles la misma garantía de libertad. En ese esfuerzo, el instrumento que ejecuta la garantía y que establece la potestad individual sobre la autodeterminación, su ejercicio, límites y protección, es la ley. Desde un punto de vista contractualista clásico, el pacto civil se ejecuta por medio de reglas jurídicas que garantizan que todos los miembros de la comunidad respetan las mismas reglas y gozan

11 La distinción entre el carácter de cada tipo de libertad, está por supuesto enfocado desde Isaiah Berlin y la ya clásica distinción que propuso entre libertad positiva y libertad negativa. En la forma en que está planteado en este texto, en sentido estricto, no se trata de ponerlo en términos de estas dos libertades, sino una libertad introspectiva, que se puede llamar libertad civil, la cual no es una libertad de "no intervención", sino otra de naturaleza activa, la libertad de poder pasar del pensamiento a la obra, de formular y ejecutar el plan de vida. ISAIAH BERLIN, Liberty: Incorporating Four Essays on Liberty, 166 (Oxford University Press, Oxford, 2002).

12 Por supuesto, están también los espacios de anomia que permiten en mayor o menor medida la libertad individual. Si esos espacios son o no parte del orden jurídico, es una pregunta que Hans Lindahl aborda en Hans Lindahl, Fault Lines of Globalization. Legal Order and the Politics of A-Legality, 39 (Oxford University Press, Oxford, 2013). 
de las mismas libertades. Así, la autodeterminación requiere una implementación que idealmente, funciona mediante legislación que no toma una posición determinada, sino que representa un valor deseable para cualquier persona dentro de la comunidad. Tal como John Rawls lo presentó en su Teoría de la justicia, el llamado velo de ignorancia tiene por efecto la creación de normas razonables, que los miembros de la comunidad estarían de acuerdo en cumplir en abstracto sin saber qué rol tendrían eventualmente que cumplir en el desarrollo de la norma y teniendo únicamente en cuenta el principio de justicia ${ }^{13}$. En este sentido, la idea liberal de autodeterminación busca la construcción de un concepto sobre la libertad, que lleva al establecimiento de normas de derecho que se reputan neutrales, pero que responden en todo caso a un principio de razonabilidad consensuado. Dicho de otro modo: si se acepta la premisa según la cual la libertad civil es la libertad socialmente acordada como tal — desde el liberalismo, al menos-, buena para todos y necesaria para cada miembro de la comunidad, las normas legales que establecen y protegen estas normas son, por consecuencia, disposiciones razonables que no establecen a favor de alguien en particular ${ }^{14}$.

Ahora bien, la neutralidad de las normas legales tiene una complicación teórica adicional que vale la pena explorar: el acompasamiento de la libertad democrática con aquella de raigambre libera $1^{15}$. La libertad democrática es aquella que ejerce la potestad de los ciudadanos de elegir a sus representantes, de tal manera que estos se encarguen a nombre de ellos de regular la conducta y el sendero de la comunidad por medio de la ley. Estas dos libertades están en permanente debate ${ }^{16}$, dado que es posible que una forma

13 John Rawls, Teoría de la justicia, 136 (Fondo de Cultura Económica, FCE, México, 2012).

14 La libertad liberal no es la misma libertad que la establecida desde el punto de vista democrático.

15 Las vertientes democrática y liberal son dos fuerzas ideológicas presentes y distintas dentro de los sistemas políticos occidentales contemporáneos. Al respecto, puede consultarse: Norberto BobBio, Liberalismo y democracia (Fondo de Cultura Económica, FCE, México, 2005).

16 Al respecto, Peter de Marneffe, Contractualism, Liberty, and Democracy, 104 Ethics, 4, 764-783 (1994). Disponible en: https://www.jstor.org/stable/2382217?seq=1\#page_scan_tab_contents. De Marneffe tiene por tesis central en su texto: "El contractualismo podría intuitivamente favorecer el principio liberal de libertad por encima del principio democrático. La posibilidad de hacer argumentos paralelos en favor de ambos principios indica, de cualquier modo, que esta intuición podría no tener base. Sin duda, el objetivo de este artículo es mostrar que el principio democrático de libertad es por lo menos compatible con el contractualismo como principio liberal. Los valores de la libertad y la democracia podrían ser balanceados, compatibilizados con el contractualismo, de tal manera que puede favorecer la voluntad popular sobre la libertad individual de forma limitada" (traduc- 
de libertad plena democrática atente contra la estructura de las libertades individuales y viceversa. De acuerdo a la forma en la que se desarrolla el poder legislativo en general, esta rama del poder público tiene los poderes para restringir y reglamentar el ejercicio de los derechos civiles y, por tanto, aquellos que permiten y protegen la autodeterminación individual. Por supuesto, las normas que expide la rama legislativa deben ajustarse a la Constitución, y no pueden transigir en materia de ciertos derechos so pena de que el juez constitucional encuentre esa incompatibilidad y elimine las normas incompatibles. De cualquier modo, los mecanismos de reforma constitucional permiten que el legislativo modifique la Constitución y, en últimas, suya es la potestad de expedir leyes al respecto de los derechos fundamentales. Aun si hay control de constitucionalidad de las reformas, la iniciativa debe partir de la manifestación popular, o de sus representantes. Dado que, por la naturaleza de la elección democrática, las mayorías disponen quiénes son las personas que legislan, y estas personas en efecto discuten y expiden las leyes, el impacto de aquello que las mayorías entienden por buena vida también hace parte del ordenamiento jurídico. Esto deja de presente un problema teórico esencial: la neutralidad de la ley está guiada necesariamente por el parecer de los representantes de las mayorías políticas de la comunidad. El anverso del argumento resulta igualmente preocupante: una autodeterminación irrestricta que no pueda ser fiscalizada o incluso confrontada, podría resultar perversa para la organización política y sus integrantes ${ }^{17}$.

La autodeterminación, entonces, al menos como norma jurídica, se pretende neutral y objetiva, pero su ejercicio legal requiere un desarrollo eminentemente político por necesidad, porque el legislativo es producto de una decisión mayoritaria que, a su vez, hace parte de la libertad en el sentido democrático. Este fenómeno ilustra cómo la autodeterminación debe vérselas en el aspecto normativo

ción propia). El debate también es muy bien ilustrado en Michael Davis, The Moral Legislature: Contractualism without an Archimedean Point, 102 Ethics, 2, 303-318 (1992). Y Paul J. Weithman, Contractualist Liberalism and Deliberative Democracy, 24 Philosophy \& Public Affairs, 4, 314-343 (1995).

17 Un ejemplo de lo anterior es el discurso de odio o hate speech. En este caso, aquellos que inciten a otros a ejercer violencia en contra de un grupo determinado de personas por su condición étnica, social, sexual o de otra naturaleza, pueden ser perseguidos criminalmente. La defensa que este tipo de casos normalmente alega es la libertad de expresión como derecho fundamental. Este tipo de caso ilustran que no todo uso de las libertades elementales es protegido por la ley. 
no en un escenario neutro - como la teoría clásica podría señalar-, sino que - como todo contenido normativo - depende en gran medida del ambiente político y de la interpretación del órgano competente, designado para el efecto por el orden constitucional. Si lo anterior tiene sentido, significa que los límites de la autodeterminación están planteados constitucionalmente, pero ejecutados legislativamente por aquellos que una vez más, son representantes de la voluntad mayoritaria de la comunidad política ${ }^{18}$. El ejemplo más a la mano en la situación política actual es el referendo de la senadora Viviane Morales, que deseaba convocar un referendo para agregar al artículo 44 de la Constitución Política un parágrafo que restringiera la adopción a parejas heterosexuales casadas o en unión marital de hecho ${ }^{19}$. Si la anterior propuesta se hubiera convertido en parte del texto constitucional, las parejas homoparentales que deseen adoptar o las personas solteras con esta misma aspiración, no podrían ejercer libremente su plan de vida, si incluía adoptar un infante. Podría entonces argüirse que la adopción es una medida de protección al infante, y no se trata de ser parte de un plan de vida de alguien más. En ese caso, diría que en la medida en que una pareja concibe y cría un infante, la decisión es de esa pareja en particular, luego sí es parte de $s u$ plan de vida.

En este estado de cosas, el escenario que este problema teórico ilustra es la razón de ser de esta investigación: qué sucede cuando los valores políticos de la comunidad están contrapuestos al ejercicio de la autodeterminación de uno o varios de sus miembros. Tal como sucede en el escenario político/legal de un legislativo, la contraposición de valores normalmente favorece a la mayoría, y aun cuando las batallas legales son conquistadas por medio de

18 Este debate está bien ilustrado en Larry Krasnoff, Consensus, Stability, and Normativity in Rawls's Political Liberalism, 95 The Journal of Philosophy, 6, 269-292 (1998). En este texto, la pregunta es sobre el constructivismo político de la teoría rawlsiana, en particular, en su idea de consenso traslapado. Jürgen Habermas debate que no todo contenido político es meramente consensual, y trae a cuento el debate sobre naturalismo contra contractualismo. Efectivamente, en la teoría jurídica, este debate se dibuja del mismo modo, pero con elementos distintos. Los escépticos morales encarnan el positivismo y se oponen a los naturalistas. Para un buen resumen de esta discusión: Carlos Santiago Nino, Derecho, moral y política. Una revisión de la teoría general del derecho (Siglo XXI Editores, Buenos Aires, 2014).

19 Colombia, Proyecto de Ley 01 de 2016, Senado, por medio de la cual se convoca a un Referendo Constitucional y se somete a consideración del pueblo un Proyecto de Reforma Constitucional por la cual se consagra la adopción de menores solo por parejas conformadas entre hombre y mujer, 430 Gaceta del Congreso, 15 de junio de 2016. Disponible en: http://www.imprenta.gov.co/gacetap/ gaceta.mostrar_documento?p_tipo $=05 \& p \_n u m e r o=01 \& p \_c o n s e c=45268$ 
la actividad judicial, la comunidad parece rechazar mayoritariamente estas determinaciones e, incluso, en algunos casos termina bloqueando el goce efectivo del derecho. Aun cuando no lo hace, de cualquier forma, la percepción del ejercicio de la autodeterminación fuera de unos cuantos cauces transitados puede aislar a los miembros de la comunidad ${ }^{20}$. En estas circunstancias, el panorama que el ejercicio de la autodeterminación plantea - al menos desde el punto de vista teórico - parece angostarse hasta el punto de que la elección se limita a algunas formas determinadas del ejercicio de la construcción de la identidad. Por ejemplo, la forma de ejercer la autodeterminación si una persona nace en una familia de situación económica precaria, puede verse comprometida si el individuo quisiera - por ejemplo - estudiar en una costosa y elitista academia de ballet. Aun si el ejemplo se modificara en el sentido de la situación económica del individuo, pero se situara en una comunidad que considera afeminado bailar ballet, el resultado sería idéntico. Lo que quiere ponerse de presente en este caso es que existir ante el mundo de manera honesta, en concordancia con lo que entiende cada individuo por su identidad, puede ser un ejercicio de suma complejidad aun viviendo en sociedades liberales que buscan proteger la autodeterminación ${ }^{21}$.

Así, esta investigación pretende dar cuenta de un aspecto particular en la discusión clásica de la teoría política y jurídica sobre el valor del individualismo frente al comunitarismo. La discrepancia

20 Sobre la igualdad como un valor fundamental al momento de entender la autodeterminación y su relación con la neutralidad: YAacov Ben-Shemesh, Neutrality without Autonomy, 24 Law and Philosophy, 5, 435-466 (2005). Este autor distingue entre una autonomía profunda y una liviana, entendiendo que la primera es a lo que apuntan los sistemas de derechos liberales, y que se garantiza mediante la neutralidad estatal: "Bajo el supuesto de la justificación pública, el requerimiento de neutralidad refleja la obligación de los ciudadanos con capacidad de autogobierno de tratar con respeto y como políticamente iguales a sus semejantes. Bajo cada visión, las razones por las cuales la neutralidad es valorada nos llevan a examinar la justificación ofrecida por las políticas estatales.

(...)

Las personas son autónomas cuando tienen opciones adecuadas entre las cuales escoger, recursos mentales y materiales suficientes que les permitan tomar decisiones informadas y racionales, y cuando poseen una sustancial libertad de acción" (traducción propia).

21 La exteriorización de una forma particular de entenderse a sí mismo y al mundo es un ejercicio eminentemente político. Muy relevante en este sentido la Parresía como la entiende Michel Foucault: la honestidad de poder expresar públicamente los propios pareceres y la convicción de que esa expresión constituye al sujeto. De alguna manera muy en sintonía con el Hier stehe ich. Ich kann nicht anders (Aqui estoy-estoy soy, no puedo hacer distinto), de Martín Lutero. Sobre la parresía como autodeterminación y agencia política, NANCY LuXON, Ethics and Subjectivity: Practices of Self-Governance in the Late Lectures of Michel Foucault, 36 Political Theory, 3, 377-402 (2008). 
se plantea sobre quién debe primar - el sujeto o la comunidadal momento de construir una idea de buena vida y de identidad. En principio, al menos, el rol del Estado y la garantía del derecho deberían encontrarse en el respeto a la autodeterminación e incluso en su protección ante las mayorías, lo que redunda en una forma de reconocimiento ${ }^{22}$.

Pasaré a una presentación del estado del arte general sobre lo hasta aquí señalado. La idea a continuación es ofrecer una perspectiva crítica del problema y orientada en dos ejes. El primero de ellos tratará la idea de buena vida y la comunidad política. El propósito de esta parte es abordar la conexión teórica entre la libertad y la felicidad, y los debates relevantes desde posturas comunitaristas e individualistas sobre la relación señalada ${ }^{23}$. En el segundo eje se hará un análisis sobre la relación entre la idea de vida buena y la estructura jurídica desde el liberalismo.

\section{A. ¿Cómo se construye el buen vivir?}

En el trayecto en el cual la existencia individual se interrelaciona con la vida en comunidad, allí tiene lugar la construcción de la identidad. En ese sentido, mediante un diálogo en cierto modo adversarial ${ }^{24}$, el individuo decide dentro de un sistema de valores determinado

22 Sobre la dinámica del reconocimiento y la protección a la autodeterminación es interesante el debate entre Charles Taylor y Jürgen Habermas, sobre cómo concebir la dinámica del reconocimiento en uno y otro autor. La posición de Taylor, de acuerdo a Maeve Cooke, es aducir que el reconocimiento en clave del liberalismo está en el respeto a la autodeterminación. Habermas problematiza este supuesto, al señalar que hay formas de reconocimiento que no necesariamente pasan por la autodeterminación. Maeve Cooke, Authenticity and Autonomy: Taylor, Habermas, and the Politics of Recognition, 25 Political Theory, 2, 258-288 (1997).

23 La idea en este apartado es poner de presente el rol de la comunidad como constructora de sus valores propios, y la forma en que estos valores configuran los tipos de formas de vida aceptados en esa comunidad.

24 Uso la palabra adversarial para describir con esto un proceso dialógico de facciones en contienda ideológica, no necesariamente material. La anterior idea proviene de Chantal Mouffe en su Retorno de lo político, en el que refina la teoría schmittiana en cuanto a la idea de "enemigo" presente en el autor, que Mouffe transfigura en una idea de "el otro". De acuerdo a lo anterior y en esta visión particular, más que un enemigo hay un contendiente en valores, y el choque de ideas y posturas es el ejercicio propio del espacio político, para evitar la violencia directa. Para Mouffe, no se trata de evadir el conflicto, sino de darle el espacio necesario en la discusión sobre los valores. Esta visión particular es de gran importancia en este texto, si se tiene en cuenta que el proceso que Schmitt propone es sobre la dicotomía amigo/enemigo, mientras que el que se plantea con Mouffe es el de una oposición intelectual e ideológica. En ambos casos, la discusión comunitaria sobre el contenido de sus valores pasa por el debate de los mismos y encuentra el espacio de lo político. CHANTAL Mouffe, El retorno de lo político. Comunidad, ciudadanía, pluralismo, democracia radical (Paidós, Barcelona, 1999). CARL Schmitt, El concepto de lo político (Alianza Editorial, Madrid, 1991). 
pues los acepta o incluye otros que confronten lo aprendido y lo obliguen a tomar decisiones sobre los que incorpora. Por supuesto, entre un sujeto que abraza todos los valores y uno que no abraza ninguno, lo más posible es que la mayoría esté en el medio de esta escala con algunas tendencias a una $u$ otra esquina. Lo descrito hasta este punto parece dar cuenta del proceso mediante el cual cada individuo combate con dos fuerzas diferenciadas y que determinan la composición de su ideario y la manera en la que observa el mundo a partir de los valores y opiniones que ha construido. Este proceso de ponderación, aceptación o descarte entre los valores de la comunidad y la reflexión individual es el punto central del debate entre las teorías individualistas y las comunitaristas en términos de la construcción de la moralidad individual que, por supuesto, propone al final una forma de valoración política. Normalmente, lo que la comunidad espera depende de factores como la proveniencia económica, la expresión de género, la procedencia familiar, el nivel educativo y muchas otras categorías. Si bien en este punto se plantea de manera muy elemental el debate, los comunitaristas no son exactamente iguales entre ellos: hay algunos más radicales en su idea de qué significa la existencia en la comunidad y otros se acercan a las teorías individualistas. Plantearé este punto a partir de algunos ejemplos. Un autor a tener en cuenta en este particular es Alasdair MacIntyre que, en su texto After Virtue, plantea una visión peculiar de lo que él denomina sociedades heroicas. En estas sociedades, la virtud es una forma de vida que se construye en circunstancias concretas mediante una práctica comunitaria particular ${ }^{25}$. Si bien MacIntyre es un abanderado del comunitarismo, en la introducción del texto es claro al señalar que más que un interés en la defensa de

25 En el capítulo concerniente a la virtud en las sociedades heroicas señala: "El ejercicio de virtudes heroicas requiere entonces tanto un tipo particular de ser humano como una estructura social particular. Por este solo hecho, una inspección de las virtudes heroicas podría parecer a simple vista irrelevante para cualquier pregunta sobre teoría y práctica moral. $\mathrm{Si}$ — para su ejercicio— las virtudes heroicas requieren la presencia de una especie de estructura social que está irrevocablemente perdida - como lo está - ¿qué relevancia existe para nosotros? Nadie puede ser un Héctor o un Gisli. La respuesta que tal vez podemos aprender de las sociedades heroicas es doble; primera: la moralidad está siempre atada a la construcción social local y particular. Las aspiraciones de una moralidad moderna, libre de particularidad son una ilusión; y segunda, no es posible tener valores sino como parte de una tradición en la cual los heredamos y nuestro entendimiento de estos valores proviene de una serie de predecesores en los cuales una serie de sociedades heroicas tiene el primer lugar" (traducción propia). Alasdair MacInTYRe, After Virtue. A Study in Moral Theory, 126-127 (University of Notre Dame Press, Notre Dame, Indiana, 2007). Disponible en: https:/epistemh. pbworks.com/f/4.+Macintyre.pdf 
las formas asociativas, su objetivo es subrayar los problemas que tiene el individualismo a la hora de establecer convincentemente un modelo moral que permita propulsar al conglomerado hacia la búsqueda de la virtud y por esa razón, cataloga el proyecto ilustrado como un fracaso, en la medida en que no logró consolidar una ética civil suficiente para dar vía a los cuestionamientos morales como una forma de preocupación política. Esta es una crítica concreta al individualismo liberal como estructura teórica que puso a la norma jurídica por encima del soberano ${ }^{26}$. En ese mismo sentido, Charles Taylor ${ }^{27}$ acompaña la teoría, al señalar que no es posible entender al individuo separado de los conflictos y paradojas morales en las cuales está histórica y socialmente inserto. La crítica de Taylor parece encaminarse a uno de los supuestos por los cuales las teorías individualistas han recibido más cuestionamientos teóricos, al tratarse de la pretensión de universalismo y homogeneidad humana $^{28}$. Otro tipo de teoría contraria al liberalismo es la expuesta por Robert Nozick. De acuerdo a su teoría, los individuos pueden asociarse de forma libre entre ellos para formar las comunidades que ellos deseen, cosa que el Estado no puede hacer, en la medida en que si el Estado pone reglas lo hace por medio de la imposición y no del consenso. De ese modo, las comunidades formadas por la voluntad de sus miembros pueden imponer reglas que pueden resultar incluso contrarias al parecer del Estado; sin embargo, las mismas resultan válidas en la medida en que fueron acordadas por

26 CARl Schmitt, Teología política, 13-36 (Trotta, Madrid, 2009).

27 Dice Taylor: "Lo que permanentemente perdemos de vista es que ser un individuo es inseparable de existir en un espacio de conflictos morales, que tiene relación con la identidad y con cómo debe ser uno. Es ser capaz de encontrar un lugar propio en este espacio, ser capaz de ocuparlo, de ser una perspectiva en el mismo. Pero, ¿no hay algo de verdad en la idea de acuerdo a la cual las personas siempre son individuos, que distinguen entre el interior y el exterior en todas las culturas? En un sentido, no hay duda de que así es. La real dificultad es distinguir los universales humanos de las constelaciones históricas y no eludir ver la segunda en la primera para que nuestro modo particular parezca de alguna manera necesaria para los seres humanos como tal, como siempre estamos tentados a hacer" (traducción propia). Charles TAYlor, Sources of Self: the Making of the Modern Identity, 112 (Harvard University Press, Cambridge, Massachusetts, 1989).

28 Tanto John Locke como Thomas Hobbes inician sus análisis en el Segundo tratado sobre el gobierno civil y Leviatán con una teoría sobre el individuo y sus apetitos, del mismo modo lo hace Juan Jacobo Rousseau en El contrato social. Al parecer, para las teorías contractualistas e individualistas, la forma del acuerdo civil (pacto social-contrato social) tiene sentido en la medida en que previene las consecuencias de los defectos a los que en principio parecemos atados por nuestra condición humana. Thomas HobBes, Leviatán, o la materia, forma y poder de una república eclesiástica y civil, 40-51 (Fondo de Cultura Económica, FCE, México, 2011). John Locke, Segundo tratado sobre el gobierno civil, 33-51 (Alianza Editorial, Madrid, 2012). 
sus miembros. La autonomía y la garantía de respeto al asociado está en el derecho de salida de la comunidad ${ }^{29}$.

De otra parte, en la perspectiva individualista, la posición de John Stuart Mill resulta fundamental para comprender el rol de la autodeterminación como llamado humano fundamental y camino hacia la felicidad individual. La reflexión se centra en la idea según la cual la existencia no es un camino de una sola vía, sino que contiene una multitud de opciones que pueden llevar a los más recónditos parajes de la experiencia, y todos ellos merecen ser recorridos por aquellos que sientan la necesidad de hacerlo de ese modo $^{30}$. En ese entendido, la experiencia humana no puede ser algo que se atestigua de manera comunitaria, sino que por necesidad está unido a la experiencia individual. Teniendo esto en cuenta, no es posible en términos comunales acotar todas las opciones que las personas observan al momento de decidir el rumbo de su vida; no es posible saber exactamente cómo piensa alguien más y alcanzar exactamente las mismas conclusiones: la vida humana es en principio solitaria ${ }^{31}$. Teniendo lo anterior en cuenta, la felicidad está en la búsqueda individual de una vida que se adecúe a los intereses y preferencias de cada ser humano, una vida que pueda expresarse en los términos más generosos posibles, y cuya variedad de opciones muestre que la libertad es el camino hacia la felicidad ${ }^{32}$. Visto de este modo, la libertad de crear un proyecto de vida está determinada por una forma particular de construcción personal.

29 Robert Nozick, Anarchy, State and Utopia, 320-323 (Wiley-Blackwell, New York, 1968).

30 Dice John Stuart Mill: "La naturaleza humana no es una máquina que se construye según un modelo y dispuesta a hacer exactamente el trabajo que le sea prescrito, sino un árbol que necesita crecer y desarrollarse por todos lados, según las tendencias de sus fuerzas interiores, que hacen de él una cosa viva”. John Stuart Mill, Sobre la libertad, 154 (Alianza Editorial, Madrid, 2005).

31 En el sentido en que cada ser humano puede conectarse a otro mediante la experiencia común y la empatía. La empatía, en este aspecto, juega un rol fundamental dentro de la teoría de las emociones morales en el entendido de que precisamente la ausencia de la misma crea individuos incapaces de relacionarse con las emociones de otros. Sobre esta discusión y su desarrollo desde la teoría humeana y kantiana: JeAnette Kennett, Autism, Empathy and Moral Agency, 52 The Philosophical Quarterly, 208, 340-357 (2002).

32 "No es vistiendo uniformemente todo lo que es individual en los seres humanos como se hace de ellos un noble y hermoso objeto de contemplación, sino cultivándolo y haciéndolo resaltar, dentro de los límites impuestos por los derechos e intereses de los demás y como las obras participan del carácter de aquellos que las ejecutan, por el mismo proceso la vida humana, haciéndose también rica, diversa y animada, provee de más abundante alimento a los altos pensamientos y sentimientos elevados y fortalece el vínculo que une todo individuo a la raza haciéndola infinitamente más digna de que se pertenezca a ella. En proporción al desenvolvimiento de su individualidad, cada persona adquiere un mayor valor para sí mismo y es capaz, por consiguiente, de adquirir un mayor valor para los demás”. John Stuart Mill, Sobre la libertad, 160 (Alianza Editorial, Madrid, 2005). 
Tal construcción, de acuerdo con Mill, está guiada por la variedad, la elección y en cierto sentido en la voluntad. Esta voluntad se expresa en la creación de un proyecto de vida. A esa construcción del proyecto de vida que constituye al individuo, es lo que llamaré identidad $^{33}$. Desde la perspectiva de Kwame Anthony Appiah, si bien la libertad efectivamente es parte importante del proceso de construcción de la identidad, esta no es tan libre como Mill se figuraba, dado que la misma está imbricada en un orden social, político y moral anterior ${ }^{34}$. La pregunta al final sobre la construcción identitaria encuentra su clímax cuando se pone en contexto de la realidad sobre las sociedades democrático/liberales actuales, que garantizan desde fórmulas morales la creación individual del proyecto de vida y de la identidad, pero que a su vez implican un estado de acontecimientos que están por fuera de la posibilidad personal de modificación. De la crítica que hace Appiah al liberalismo emerge la siguiente pregunta: ¿Cuál es la posibilidad de escoger el proyecto de vida en comunidades dentro de las cuales hay una alta transferencia de valores entre el conglomerado y el individuo? La tesis de Appiah se encamina a probar que esta ponderación no solo es posible, sino que las comunidades realizan este proceso como medio de protección de sí mismas.

33 Si bien hay muchas formas de identidad, en este caso me preocupa esencialmente la identidad individual y cómo esta trasluce al espacio de la comunidad. Sin duda, esto es tomar una posición sobre a qué tipo de identidad me refiero, pero precisamente por ello se hace esta salvedad.

34 Dice Appiah: “... ¿debe el Estado invadir las almas de sus ciudadanos? Cuando la pregunta se formula de esa manera, muchos de nosotros retrocederemos espantados ante semejante perspectiva; y existen razones válidas para que reaccionemos así. Porque el discurso sobre la formación del alma huele demasiado a esa clase de indiscreta interferencia gubernamental que [Karl] Popper hacía bien en temer: a todos los conocidos intentos fatídicos de transformar la naturaleza humana en virtud de alguna visión utópica. Recurriendo a una solemne imagen marcial, [Leonard Trelawny] Hobhouse llamó 'ciudadela interior' a la libertad de pensamiento, y no se trata de algo que se nos ocurra invadir con ligereza. Sin embargo, como es posible advertir luego de un momento de reflexión, hay otros aspectos a considerar. Nunca ha existido un Estado que no ejerza una influencia en el carácter de sus ciudadanos, esa ciudadela interior puede parecerse más a un café, que existe para todos los grupos que bullen en su interior. La autonomía, ya lo sabemos, se describe convencionalmente como el ideal de autoría de uno mismo. Si somos nuestros propios amos, son el Estado y la sociedad los que proporcionan las herramientas y los contextos de nuestra autoría: si bien es posible que nosotros configuremos nuestro propio yo, son otros los que configuran nuestra configuración. Y entonces, si el Estado no puede sino influir en nuestra alma, es justo que nos preguntemos cómo lo hace y cómo debe hacerlo". Kwame Anthony Appiah, La ética de la identidad, 235 (Katz Editores, Buenos Aires, Madrid, 2007). 


\section{B. Comunidad, Individuo y proyecto de vida}

Hay para empezar, una postura fundamental individualista: la comunidad es la suma de los individuos ${ }^{35}$, y el individuo es la partícula elemental de la sociedad. La razón para partir de esta postura es la que enuncia Georg Wilhelm Friedrich Hegel en Jenaer Realphilosophie, retomada por Axel Honneth ${ }^{36}$. En ese texto, Hegel hace una contrapropuesta a Thomas Hobbes en cuanto al estado de guerra en el que se encuentran los hombres, producto de su persecución de la gloria, la competencia y la desconfianza. Aquí, Hegel supone que la violencia propia del estado de guerra proviene de una fuente anterior, de una distinta a la fuerza de la ambición y la gloria, a saber: la ausencia de la percepción del otro como sujeto, la falta de entenderlo como propio, como un par. En suma, la falta del reconocimiento es lo que genera, antes que la fuerza de la gloria, el estado de la guerra. Así, las manifestaciones más físicas o materiales del ser humano que dispone de otro o de sus bienes de manera desconsiderada o abiertamente despótica, no evalúa el hecho de que sus actos dañan a un semejante, a otro igual que él $l^{37}$.

El reconocimiento como parte del proceso de formación comunitaria explica una parte del espectro, pero es solo uno de los procesos necesarios de formación de lo colectivo. En ese sentido, las

35 De acuerdo a las posturas esbozadas anteriormente, los comunitaristas por supuesto no están de acuerdo con una afirmación tan cerrada y categórica como esa.

36 Axel Honneth, Struggle for Recognition. The Moral Grammar of Social Conflicts, 31-63 (The MIT Press, Cambridge, Massachusetts, 1995).

37 La reconstrucción de la teoría de un joven Hegel arroja tres elementos para poder entender la dinámica intersubjetiva de las comunidades, a saber: autoconfianza, autorrespeto y autoestima, que tienen como base tres tipos distintos de búsqueda de reconocimiento: el amor, el derecho y la solidaridad. Por un lado, la autoconfianza surge al momento de la separación entre el niño y la madre, cuando el primero empieza a concebirse como un ser independiente a su progenitora y percibe la posibilidad de éxito o de fracaso como sucesos que afectan su propia existencia, no ya atado a la existencia de la madre o de un "protector" que salvaguarda en todo tiempo sus intereses, sino como los actos que realiza recaen directamente sobre sí. Esta autoconfianza surge desde la relación de amor, como describe Honneth en la primera parte de su texto. En síntesis, el ser se percibe a sí mismo y entiende que sus acciones son suyas y las consecuencias que acarrean. De otra parte, el autorrespeto emerge como consecuencia directa de lo anterior, cuando el ser que es miembro de la comunidad política entiende que por el hecho de encontrarse en una comunidad determinada tiene ciertos derechos que pueden ser desarrollados en este ámbito y le permiten interactuar en igualdad de condiciones con otros seres, miembros de la misma comunidad política. Por último, queda la autoestima, que es poder visibilizarse y relacionarse de manera simétrica con los otros miembros de la comunidad, entendiendo en ellos la misma entidad que cada ser por medio del autorrespeto ha descubierto en sí mismo. Esto permite a la comunidad política entenderse como la urdimbre de pares que conviven $\mathrm{y}$ toman las decisiones pertinentes para todos aquellos que son parte en la misma. Lo anterior es aquello a lo que Honneth llama solidaridad. 
tensiones alrededor de los derechos y su implementación parecen estar fincadas en el esfuerzo ético-racionalista ${ }^{38}$ de lograr comunidades estables y plenas de opciones identitarias para sus miembros, y las determinaciones que como un conglomerado social toma el organismo sobre lo que entiende por un estilo de vida deseable o incluso, respetable. Ahora bien, la herramienta teórico-jurídica en virtud de la cual se expresa el principio de neutralidad que permite la formación del plan de vida autodeterminado, es el positivismo jurídico. Lo anterior lo afirmo en la medida en que los cultores y teóricos de esta teoría descriptiva buscan separar el derecho de otro tipo de órdenes normativos. En esa medida, ellos pretenden el derecho como neutral, lo que cobra sentido con la teoría liberal del derecho. Aquí posiblemente encontramos una primera fisura entre lo que el proyecto liberal anhela y lo que efectivamente es posible en términos de lo normativo-comunitario en el entendido de que dentro del proyecto clásico positivista jurídico ${ }^{39}$, las normas jurídicas y las normas morales comparten su poder disuasivo, pero no así el aspecto coercitivo por el que las normas de derecho se destacan. De este modo, lo propiamente obligatorio son las normas jurídicas, de acuerdo a la teoría positivista estricta ${ }^{40}$. En esta misma teoría, la moral es un orden normativo que no es exigible, dado que sus contenidos no provienen de decisiones tomadas de

38 Si bien el acuerdo sobre los derechos parece un hito histórico en Occidente, la lectura de tal acuerdo es disímil en cuanto a si los derechos representan un avance moral humano (postura ético-racionalista) o se trata nada más de una teoría histórica y contingentemente situada sobre lo que entendemos por ser humano. Al respecto, Norberto BobBio, El tiempo de los derechos, 111 (Editorial Sistema, Madrid, 1990).

39 Dentro de la teoría positivista, si bien el orden moral y el jurídico utilizan conceptos similares, están divididos por la naturaleza de ambos sistemas normativos. En este particular, el abanderado es Hans Kelsen, quien distingue con mucha precisión los confines de uno y otro ordenamiento: "Cuando en una regla de derecho expresamos que la consecuencia debe seguir a la condición, no adjudicamos a la palabra 'debe' ninguna significación moral. Que tal conducta sea prescrita por el derecho no significa que lo sea igualmente por la moral. La regla de derecho es un instrumento que sirve para describir el derecho positivo tal como ha sido establecido por las autoridades competentes. De aquí se desprende que el derecho positivo y la moral son dos órdenes normativos distintos uno del otro. Esto no significa que sea menester renunciar al postulado de que el derecho debe ser moral, puesto que, precisamente, solo considerando al orden jurídico como distinto de la moral, cabe calificarlo de bueno o de malo.

Sin duda, el derecho positivo puede, en ciertos casos, autorizar la aplicación de normas morales. Es decir que delega en la moral el poder de determinar la conducta por seguir. Pero desde que una norma moral es explicada en virtud de una norma jurídica adquiere, por tal circunstancia, el carácter de norma jurídica". Hans Kelsen, Teoría pura del derecho, 45 (Editorial Universitaria de Buenos Aires, Eudeba, Buenos Aires, 2009).

40 "Pacto de la paz" Thomas Hobbes. Thомas HobBes, Leviatán, o la materia, forma y poder de una república eclesiástica y civil, 107 (Fondo de Cultura Económica, FCE, México, 2011). 
forma consensuada, sino de preceptos que no pueden ser negociados, cambiados o transigidos en modo alguno ${ }^{41}$. Así, el modelo voluntarista que entrega la creación normativa a los miembros de un conglomerado social determinado, se opone radicalmente a un modelo normativo naturalista que más que establecer normas las "descubre": las busca dentro del orden natural del universo y la razón para hacerlas obligatorias por medio de un instrumento jurídico ${ }^{42}$. El modelo positivista se acompasa con el modelo liberal, en el sentido de que su pretensión es separar el ámbito moral del legal, con el fin de procurar la neutralidad de la ley. En ese sentido, es una manifestación de cierto escepticismo moral ${ }^{43}$, que busca separar tanto como se pueda la creación e implementación de las leyes de razones morales ${ }^{44} \mathrm{y}$, en consecuencia, si la moralidad no

41 "Toda norma jurídica, como todos los juristas saben, es imperativo-atributiva, esto es, atribuye una obligación a un sujeto en el mismo momento en el que atribuye un derecho al otro sujeto. Ahora bien, el iusnaturalismo clásico y medieval había puesto el acento sobre el aspecto imperativo de la ley natural más que sobre el aspecto atributivo; mientras la doctrina moderna de los derechos naturales pone el acento sobre el aspecto atributivo más que sobre el imperativo. La ley natural, en la concepción del iusnaturalismo tradicional, era una regla de conducta que tenía sobre todo como destinatarios a los soberanos a los que imponía la obligación de ejercer el poder respetando algunos principios morales supremos. Que a este deber de los gobernantes correspondiese un derecho correlativo de los súbditos a pretender que los mismos gobernantes respetasen el deber era dudoso; los súbditos tenían sobre todo el deber de obedecer también a los malos soberanos, al menos según las doctrinas que representaban las opiniones más comunes". Norberto BoвBIO, El tiempo de los derechos, 41 (Editorial Sistema, Madrid, 1990).

42 Sobre la codificación y su establecimiento, y sobre la teoría ético-racional que se deslinda de ella: Giovanni Tarello, Cultura jurídica y política del derecho, 41, 43 (Fondo de Cultura Económica, FCE, Buenos Aires, 1995).

43 "Los filósofos escépticos de la justicia — quienes argumentan que la justicia está solo en el ojo del observador, o que los reclamos de justicia son solo proyecciones de emociones- a menudo suponen que sus propias teorías son neutrales. Pero sería muy sorprendente encontrar un filósofo defendiendo una concepción positiva de la justicia - que la justicia política consiste en los arreglos que maximizan la riqueza de una comunidad, por ejemplo - que creyera que su teoría no sea ella misma una teoría normativa. Los filósofos de la justicia entienden que ellos están tomando partido, que sus teorías son tan normativas como las afirmaciones acerca de la justicia y la injusticia que los políticos, editorialistas y ciudadanos hacen. Los conceptos políticos más densos de libertad, igualdad y democracia cumplen el mismo rol en la discusión política, y las teorías acerca de la naturaleza de esos conceptos también son normativas. Estamos de acuerdo en que la democracia es de gran importancia, pero estamos en desacuerdo sobre cuál concepción de la democracia da cuenta y expresa de mejor manera esa importancia. Ninguno de quienes discuten acerca de si acaso la revisión judicial es inconsistente con la democracia aceptaría que la cuestión sobre lo que la democracia realmente es, adecuadamente entendida, es un asunto descriptivo que ha de ser establecido estudiando, por ejemplo, cómo la mayoría de la gente usa la palabra 'democracia'. Ellos entienden que su disputa es profunda, esencialmente sustantiva". RONALD DWORKIN, El postscript de Hart y el sentido de la filosofía política, en La justicia con toga, 159-204 (Marcial Pons, Madrid, 2007).

44 Hannah Arendt describe históricamente las razones que dieron paso a los totalitarismos en Europa a mediados del siglo XX, al mostrar cómo los climas imperialistas cobraron un precio en los Estados nacionales y el proceso social que acompañó esos cambios. HanNAH ARENDT, Los orígenes del totalitarismo (Alianza Editorial, Madrid, 1968). 
está determinada por la ley, queda en manos del individuo y la forma en la que asuma dentro de su identidad los valores que elija sin más límite que la legalidad.

Ahora bien, la literatura sobre la formación de la identidad y la autodeterminación en Colombia ha estado encaminada en dos sentidos: el primero: aspectos puntuales de la discusión del multiculturalismo y los indígenas y moradores originarios. En ese sentido, el tratamiento de estos conceptos ha sido operativo en áreas como la sociología, la antropología y la historia ${ }^{45}$. Del mismo modo, en literatura jurídica especializada, el eje de discusión siguen siendo los grupos indígenas y su inserción en el proyecto nacional y constitucional colombiano ${ }^{46}$. Si bien en esta literatura el debate sobre la identidad es parte fundamental bien sea como un concepto teóricamente relevante, o como parte de un discurso de pluralismo legal, la reflexión desde la filosofía moral y política resulta tangencial en el mejor de los casos. Por otro lado, las revistas de filosofía nacional han publicado trabajos al respecto ${ }^{47}$; sin embargo, los mismos ilustran debates filosóficos sin atarlos al elemento normativo o legal.

45 Al respecto, Luis Carlos Castillo \& Heriberto Cairo-Carou, Reinvención de la identidad étnica, nuevas territorialidades y redes globales: el Estado multiétnico y pluricultural en Colombia y Ecuador, 3 Sociedad y Economía, 55-76 (2002). Disponible en: http://sociedadyeconomia.univalle.edu.co/ index.php/sye/article/view/194. Christian Gros \& Ángela OCHOA, Identidades indias, identidades nuevas. Algunas reflexiones a partir del caso colombiano, 60 Revista Mexicana de Sociología, 4, 181-207 (octubre-diciembre de 1998).

46 Sorily Figuera-Vargas \& Andrea Ariza-Lascarro, Derecho a la autodeterminación de los pueblos indígenas en el ordenamiento jurídico colombiano, 53 Revista de Estudios Sociales, 65-76 (2015). Disponible en: https://res.uniandes.edu.co/pdf/descargar.php?f=./data/Revista_No_53/n53a06.pdf. También ver: CARLos ANDRÉs TOBAR-TovaR, Sobre la instrumentalización de la identidad en el marco de las luchas por el reconocimiento político de los pueblos indígenas en Colombia, 19 Perifèria, 2, 124-143 (2014). Disponible en: http://revistes.uab.cat/periferia/article/view/vol19-n2-Tobar/pdf-es. Y Felipe Arturo Robledo-Martínez, Identidad cultural, salud social y Estado Social de Derecho. El caso "Tesoro Quimbaya" Quindio, Colombia, 17 Revista de Salud Pública, 4, 636-646 (2015). Disponible en: http://revistas.unal.edu.co/index.php/revsaludpublica/article/view/48601/54011

47 José Francisco Zárate-Ortiz, La identidad como construcción social desde la propuesta de Charles Taylor, 23 Eidos: Revista de Filosofia de la Universidad del Norte, 117-134 (2015). Disponible en: http://www.redalyc.org/pdf/854/85439039007.pdf. Facundo García-Valverde, Agencia política y legitimidad en la democracia deliberativa, 22 Eidos: Revista de Filosofia de la Universidad del Norte, 225-252 (2014). Disponible en: http://rcientificas.uninorte.edu.co/index.php/eidos/article/ view/5421/pdf_158 


\section{CONCLUSIONES}

Al final, las reflexiones en torno a la capacidad o no de los derechos de hacer a los seres humanos más libres y autónomos, refiere a algunas formas de ver la estructura jurídica. En una de ellas, el derecho mantiene arreglos sociales más amplios, en los cuales las clases dominantes de la sociedad exteriorizan y convierten su moral y forma de vida en un patrón jurídico obligatorio que perpetúa sus valores y así, su permanencia como sección dominante en su medio. Por otro lado, hay quienes ven en el derecho una lucha emancipatoria que constantemente guía a los hombres a la libertad y a un mejor entendimiento de cuál es la relación entre sus semejantes. Para ponerlo en las palabras de Hannah Arendt en ¿Qué es la autoridad?: "Donde el escritor liberal ve un progreso esencialmente asegurado en la dirección de la libertad, que es temporalmente interrumpido por las fuerzas oscuras del pasado, el conservador ve un proceso de condena que inició con el debilitamiento de la autoridad, así que la libertad, después de haber perdido las restricciones y límites que protegían sus fronteras, se volvió débil, indefensa y se encuentra en vía de ser destruida".

Una tercera postura sugiere que el derecho es un espacio de lucha, de batallas con agendas de distintas secciones de la sociedad en las que avances y retrocesos suceden constantemente, no de una forma definitiva, sino para reflejar valores en disputa que logran posicionarse en momentos históricos determinados. Esta pugna permanente entre posturas contrarias hace que la idea de neutralidad en la aplicación de la ley y la neutralidad del Estado encuentren serios problemas en la práctica, dado que mantener una aplicación neutral del derecho en medio de una permanente oposición entre valores políticos podría ser una tarea que las reglas de interpretación y aplicación del derecho estén en una posición muy precaria de cumplir.

De este modo, aun si las teorías descriptivas del derecho procuran delimitar el accionar legal a unos cauces metodológicos determinados, y en ese sentido procuran mantener desde el punto de vista teórico la posibilidad de un juicio racional que posibilite la neutralidad de la aplicación del derecho, siempre queda la duda sobre si dicha aplicación depende necesariamente de la posibilidad 
de acceder a una buena razón jurídica o a otro tipo de motivación que provenga desde otro espectro del operador del sistema.

En ese escenario, se hace necesario evaluar si el ordenamiento jurídico puede efectivamente formar el comportamiento ${ }^{48} \mathrm{o}$ si el mismo es más bien un lugar de recepción, donde bien puede capturarse el espíritu de una época y sus valores predominantes ${ }^{49}$; más que modificarlos o imponerlos, cabe preguntarse si proteger la autodeterminación por medio de los derechos fundamentales y la neutralidad moral del Estado, es posible cuando se trata de proyectos de vida contramayoritarios.

48 Joseph Raz, The Authority of Law: Essays on Law and Morality, capítulo 11 (Oxford University Press, Oxford, 2009).

$49 \mathrm{Su}$ Zeitgeist, como dijo Oliver Wendell Holmes. Oliver Wendell Holmes, The Path of the Law, 10 Harvard Law Review, 8, 457-478 (1897). 


\section{BIBLIOGRAFÍA}

\section{Libros}

Appiah, Kwame Anthony, La ética de la identidad (Katz Editores, Buenos Aires, Madrid, 2007).

Arendt, Hannah, Los orígenes del totalitarismo (Alianza Editorial, Madrid, 1968).

Berlin, Isaiah, Liberty: Incorporating Four Essays on Liberty (Oxford University Press, Oxford, 2002)

Bobbio, Norberto, El tiempo de los derechos (Editorial Sistema, Madrid, 1990).

Bobbio, Norberto, Liberalismo y democracia (Fondo de Cultura Económica, FCE, México, 2005).

Dworkin, Ronald, La justicia con toga (Marcial Pons, Madrid, 2007).

Gewirth, Alan, Self Fulfillment (Princeton University Press, Princeton, New Jersey, 1998).

HobBes, Thomas, Leviatán, o la materia, forma y poder de una república eclesiástica y civil (Fondo de Cultura Económica, FCE, México, 2011).

Honneth, Axel, Struggle for Recognition. The Moral Grammar of Social Conflicts (The MIT Press, Cambridge, Massachusetts, 1995).

Kelsen, Hans, Teoría pura del derecho (Editorial Universitaria de Buenos Aires, Eudeba, Buenos Aires, 2009).

Kennedy, Duncan, A Critique of Adjudication (fin de siècle) (Harvard University Press, Cambridge, Massachusetts, 1997).

Lindahl, Hans, Fault Lines of Globalization. Legal Order and the Politics of A-Legality (Oxford University Press, Oxford, 2013).

Locke, JoHn, Segundo tratado sobre el gobierno civil (Alianza Editorial, Madrid, 2012).

MacIntyre, Alasdair, After Virtue. A Study in Moral Theory (University of Notre Dame Press, Notre Dame, Indiana, 2007). Disponible en: https://epistemh.pbworks. com/f/4.+Macintyre.pdf

MacKinnon, Catharine A. \& Posner, Richard, Derecho y pornografía (Siglo del Hombre Editores, Bogotá, 1997).

Merry, Sally Engle; Griffiths, John \& Tamanaha, Brian Z., Pluralismo jurídico (Siglo del Hombre Editores, Bogotá, 2007).

Mill, John Stuart, Sobre la libertad (Alianza Editorial, Madrid, 2005).

Mouffe, Chantal, El retorno de lo político. Comunidad, ciudadanía, pluralismo, democracia radical (Paidós, Barcelona, 1999).

Nino, Carlos Santiago, Derecho, moral y política. Una revisión de la teoría general del derecho (Siglo XXI Editores, Buenos Aires, 2014).

Rawls, John, Liberalismo político (Fondo de Cultura Económica, FCE, México, 2015). 
Rawls, John, Teoría de la justicia (Fondo de Cultura Económica, FCE, México, 2012).

Raz, Joseph, The Authority of Law: Essays on Law and Morality (Oxford University Press, Oxford, 2009).

Raz, Joseph, The Morality of Freedom (Oxford University Press, Oxford, 1986).

Schmitt, CARL, El concepto de lo político (Alianza Editorial, Madrid, 1991).

Schmitt, Carl, Teología política (Trotta, Madrid, 2009).

Tarello, Giovanni, Cultura jurídica y política del derecho (Fondo de Cultura EconómicA, FCE, Buenos Aires, 1995).

Taylor, Charles, Sources of Self: the Making of the Modern Identity (Harvard University Press, Cambridge, Massachusetts, 1989).

\section{Contribución en obras colectivas}

Oshana, Marina A. L., Autonomy and Self-Identity, en Autonomy and the Challenges of LiberAlism, 77-97 (John Christman \& Joel Anderson, eds., Cambridge University Press, Cambridge, 2005).

\section{Revistas}

Yaacov Ben-Shemesh, Neutrality without Autonomy, 24 Law and Philosophy, 5, 435-466 (2005).

Buss, Sarah, Autonomous Action: Self-Determination in the Passive Mode, 122 Ethics, 4, 647-691 (2012). Disponible en: http://www.jstor.org/stable/pdf/10.1086/666328. pdf?refreqid=excelsior $\% 3 \mathrm{Aba} 601 \mathrm{e} 4 \mathrm{~d} 03 \mathrm{a} 3 \mathrm{~b} 33973 \mathrm{f} 683 \mathrm{c} 8 \mathrm{c} 2503585$

Castillo, luis Carlos \& Cairo-Carou, Heriberto, Reinvención de la identidad étnica, nuevas territorialidades y redes globales: el Estado multiétnico y pluricultural en Colombia y Ecuador, 3 Sociedad y Economía, 55-76 (2002). Disponible en: http:// sociedadyeconomia.univalle.edu.co/index.php/sye/article/view/194

Cooke, Maeve, Authenticity and Autonomy: Taylor, Habermas, and the Politics of Recognition, 25 Political Theory, 2, 258-288 (1997).

Davis, Michael, The Moral Legislature: Contractualism without an Archimedean Point, 102 Ethics, 2, 303-318 (1992).

Dworkin, Ronald, Una cuestión de principios (Siglo XXI Editores, Madrid, Buenos Aires, 2012).

Figuera-Vargas, Sorily \& Ariza-Lascarro, Andrea, Derecho a la autodeterminación de los pueblos indígenas en el ordenamiento jurídico colombiano, 53 Revista de Estudios Sociales, 65-76 (2015). Disponible en: https://res.uniandes.edu.co/pdf/ descargar.php?f=./data/Revista_No_53/n53a06.pdf

García-Valverde, Facundo, Agencia politica y legitimidad en la democracia deliberativa, 22 Eidos: Revista de Filosofía de la Universidad del Norte, 225-252 (2014). Disponible en: http://rcientificas.uninorte.edu.co/index.php/eidos/article/ 
view/5421/pdf_158

Gros, Christian \& OchoA, Ángela, Identidades indias, identidades nuevas. Algunas reflexiones a partir del caso colombiano, 60 Revista Mexicana de Sociología, 4, 181-207 (octubre-diciembre de 1998).

Holmes, Oliver Wendell, The Path of the Law, 10 Harvard Law Review, 8, 457-478 (1897).

Kennett, Jeanette, Autism, Empathy and Moral Agency, 52 The Philosophical Quarterly, 208, 340-357 (2002).

Krasnoff, Larry, Consensus, Stability, and Normativity in Rawls's Political Liberalism, 95 The Journal of Philosophy, 6, 269-292 (1998).

Luxon, NAncy, Ethics and Subjectivity: Practices of Self-Governance in the Late Lectures of Michel Foucault, 36 Political Theory, 3, 377-402 (2008).

Marneffe, Peter de, Contractualism, Liberty, and Democracy, 104 Ethics, 4, 764-783 (1994). Disponible en: https://www.jstor.org/stable/2382217?seq=1\#page_scan_ tab_contents

Mason, Andrew D., Autonomy, Liberalism and State Neutrality, 40 The Philosophical Quarterly, 161, 433-452 (1990).

Nozick, Robert, Anarchy, State and Utopia (Wiley-Blackwell, New York, 1968).

Robledo-Martínez, Felipe Arturo, Identidad cultural, salud social y Estado Social de Derecho. El caso "Tesoro Quimbaya" Quindío, Colombia, 17 Revista de Salud Pública, 4, 636-646 (2015). Disponible en: http://revistas.unal.edu.co/index.php/ revsaludpublica/article/view/48601/54011

Tobar-Tovar, Carlos Andrés, Sobre la instrumentalización de la identidad en el marco de las luchas por el reconocimiento politico de los pueblos indígenas en Colombia, 19 Perifèria, 2, 124-143 (2014). Disponible en: http://revistes.uab.cat/periferia/ article/view/vol19-n2-Tobar/pdf-es

Tushnet, Mark, An Essay on Rights, 62 Texas Law Review, 8, 1363-1402 (1984). Disponible en: http://www.dariaroithmayr.com/pdfs/assignments/Tushnet, $\% 20$ Essay\%20on\%20Rights.pdf

Weithman, Paul J., Contractualist Liberalism and Deliberative Democracy, 24 Philosophy \& Public Affairs, 4, 314-343 (1995).

ZÁrate-Ortiz, José Francisco, La identidad como construcción social desde la propuesta de Charles Taylor, 23 Eidos: Revista de Filosofia de la Universidad del Norte, 117-134 (2015). Disponible en: http://www.redalyc.org/pdf/854/85439039007.pdf

\section{Normatividad colombiana}

Colombia, Ley 581 de 2000, por la cual se reglamenta la adecuada y efectiva participación de la mujer en los niveles decisorios de las diferentes ramas y órganos del poder público, de conformidad con los artículos 13,40 y 43 de la Constitución Nacional y se dictan otras disposiciones, 44.026 Diario Oficial, 31 de mayo 2000. Disponible en: http://www.secretariasenado.gov.co/senado/basedoc/ley_0581_2000.html 


\section{Proyectos de ley colombianos}

Colombia, Proyecto de Ley 01 de 2016, Senado, por medio de la cual se convoca a un Referendo Constitucional y se somete a consideración del pueblo un Proyecto de Reforma Constitucional por la cual se consagra la adopción de menores solo por parejas conformadas entre hombre y mujer, 430 Gaceta del Congreso, 15 de junio de 2016. Disponible en: http://www.imprenta.gov.co/gacetap/gaceta. mostrar_documento?p_tipo $=05 \&$ p_numero $=01 \&$ p_consec $=45268$

\section{Jurisprudencia colombiana}

Colombia, Corte Constitucional, Sentencia C-355-06, 10 de mayo de 2006, magistrados ponentes Jaime Araújo-Rentería, Clara Inés Vargas-Hernández. Disponible en: http://www.corteconstitucional.gov.co/relatoria/2006/C-355-06.htm

Colombia, Corte Constitucional, Sentencia C-075-07, 7 de febrero de 2007, magistrado ponente Rodrigo Escobar-Gil. Disponible en: http://www.corteconstitucional. gov.co/relatoria/2007/c-075-07.htm

\section{Direcciones web, medios de comunicación}

Revista Semana, El poder gay en Colombia (25 de junio de 2016). Disponible en: http:// www.semana.com/nacion/articulo/lgbt-como-progresismo-e-igualdad-dederechos $/ 479178$ 